\title{
IMPACT OF COUNTDOWN GROUND LED LIGHTS ON TRAFFIC FLOW EFFICIENCY AT SIGNALIZED INTERSECTIONS: A DRIVING SIMULATOR STUDY
}

\author{
Qinaat Hussain, Wael K. M. Alhajyaseen, Kris Brijs, Ali Pirdavani, Tom Brijs
}

\section{Introduction}

Unnecessary stopping at signalized intersections during yellow interval reduces traffic flow efficiency

Difficult to make appropriate decisions at the onset of yellow interval

\section{Objectives}

To investigate the impact of countdown ground LED dynamic lights on traffic flow efficiency during inter-green period at signalized intersections

The countdown system is aimed at visualizing the inter-green period by means of a countdown system

\section{Apparatus}

Driving simulator at QTTSC was used

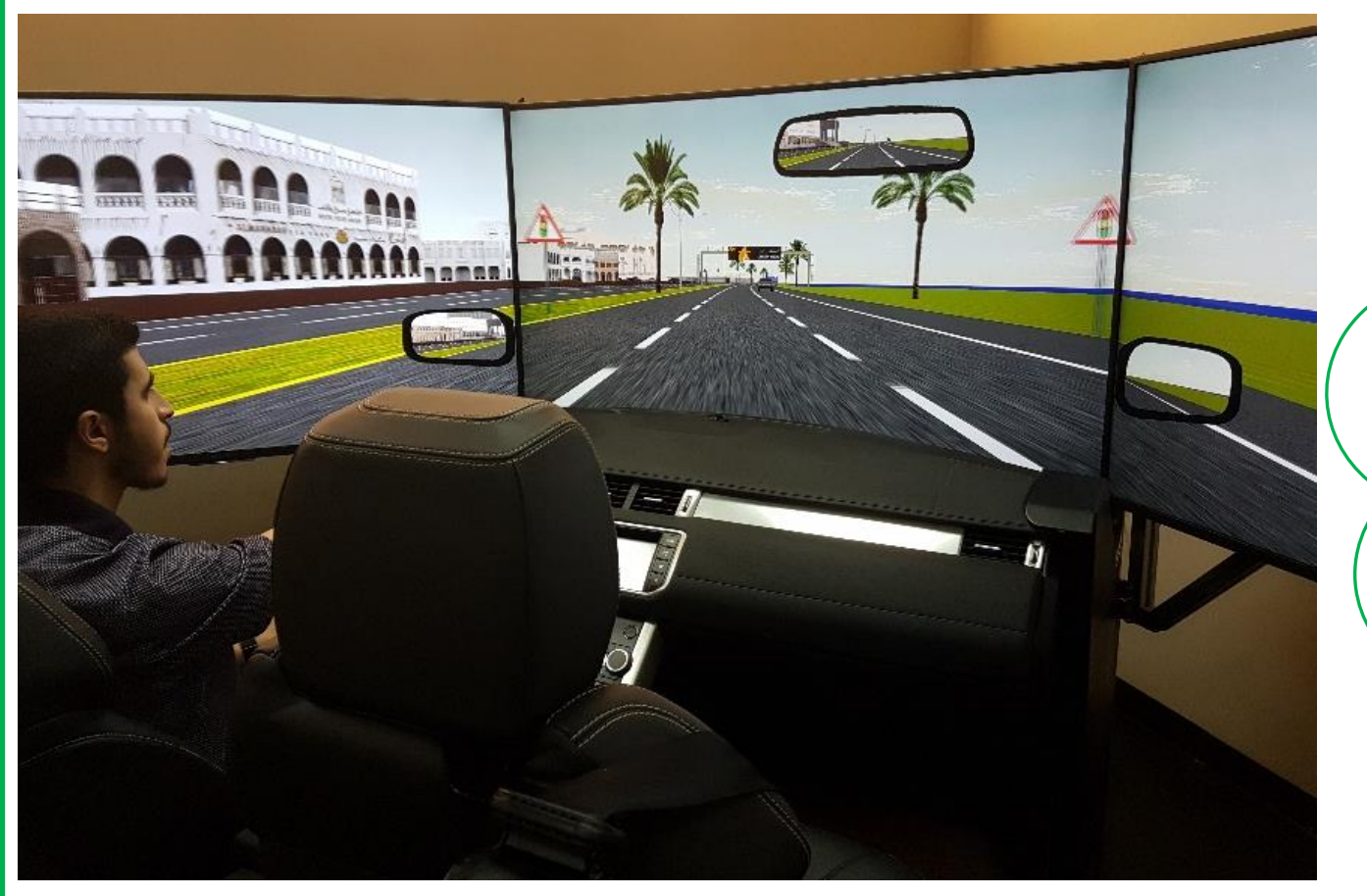

$135^{\circ}$ horizontal view $5760 \times 1080$ pixels resolution

Participants

67 participants with a valid Qatari driving license

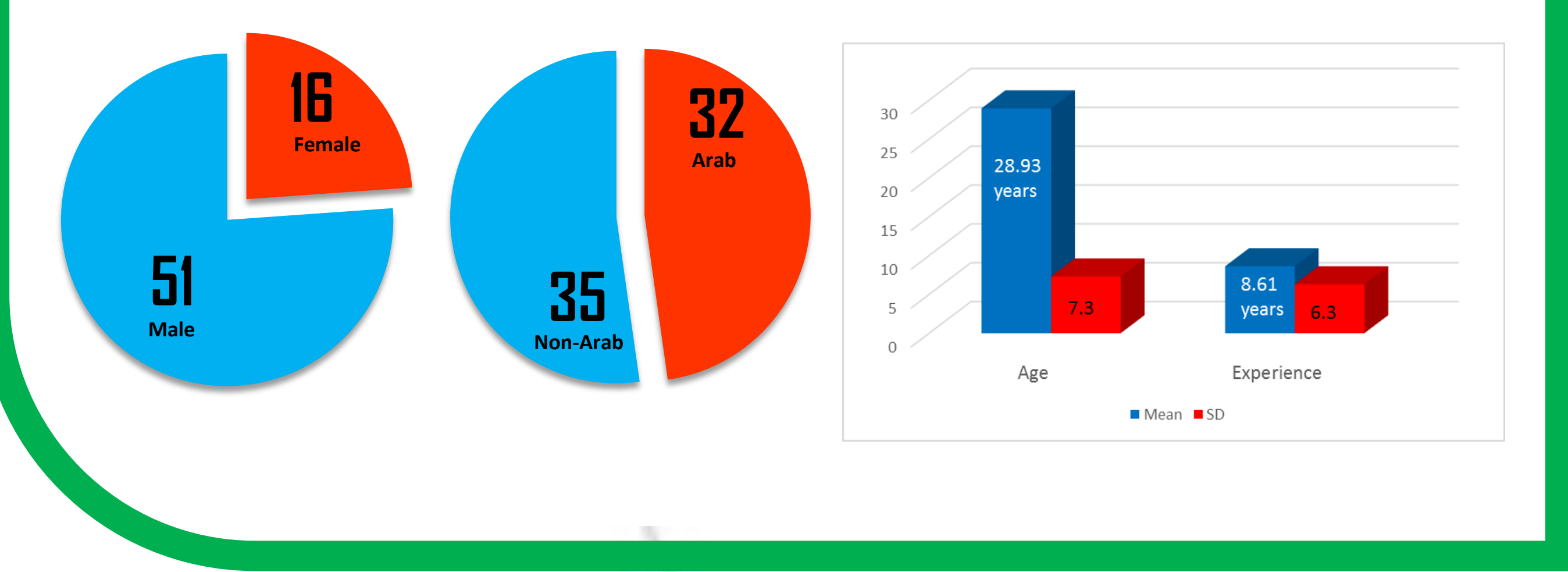

\section{STUDY DESIGN}

\section{Situation}

Option zone

At the onset of yellow interval: $65 \mathrm{~m}$ from the stop line

At the onset of flashing green: $125 \mathrm{~m}$ from the stop line

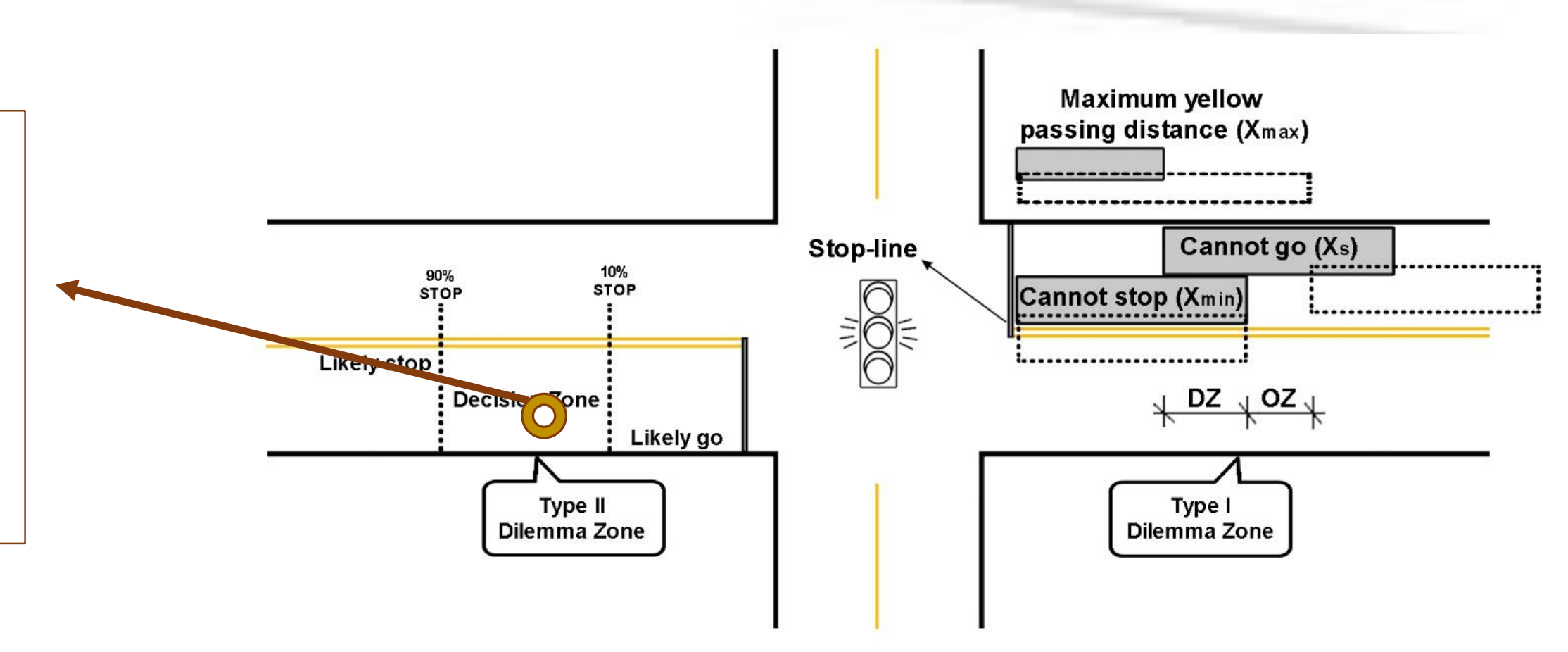

\section{Scenarios}
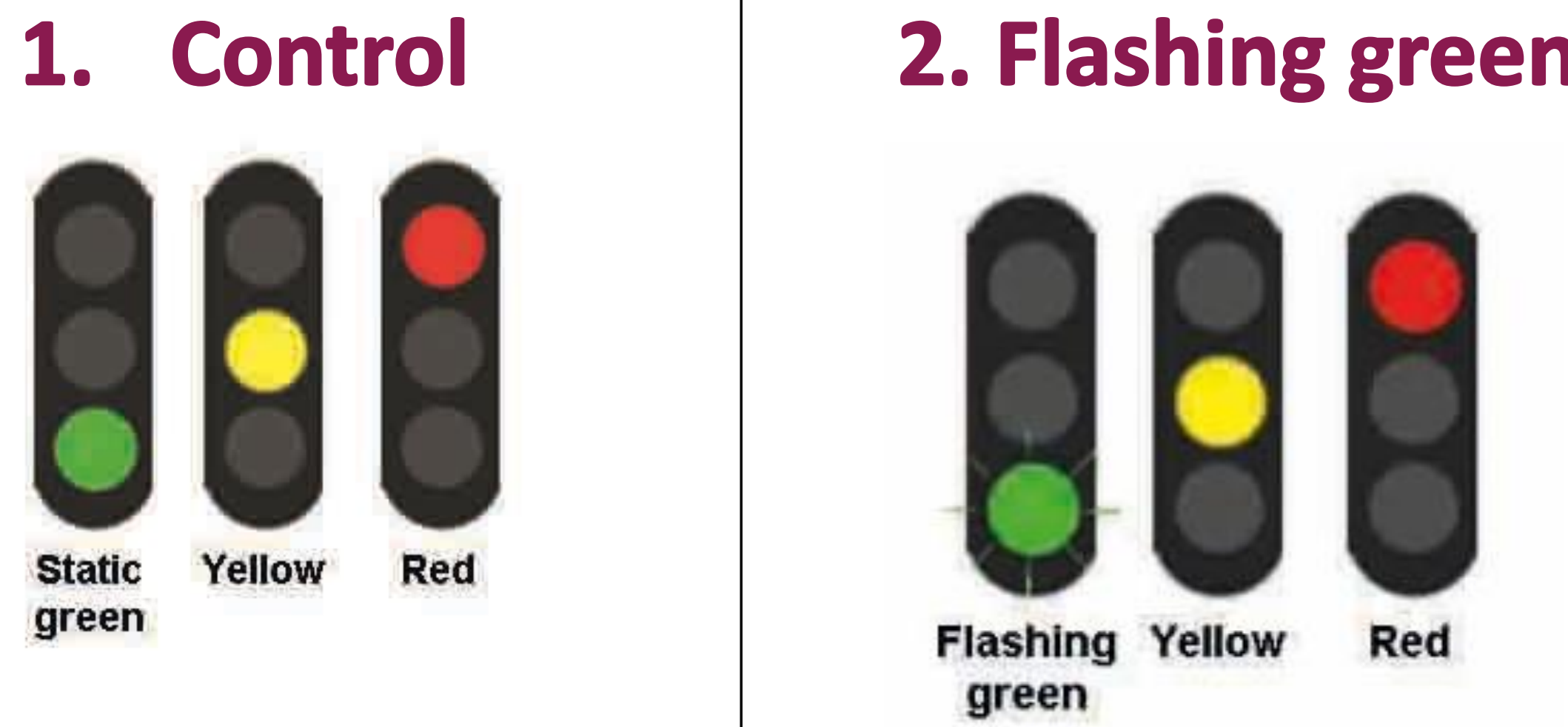

\section{Green LED lights}

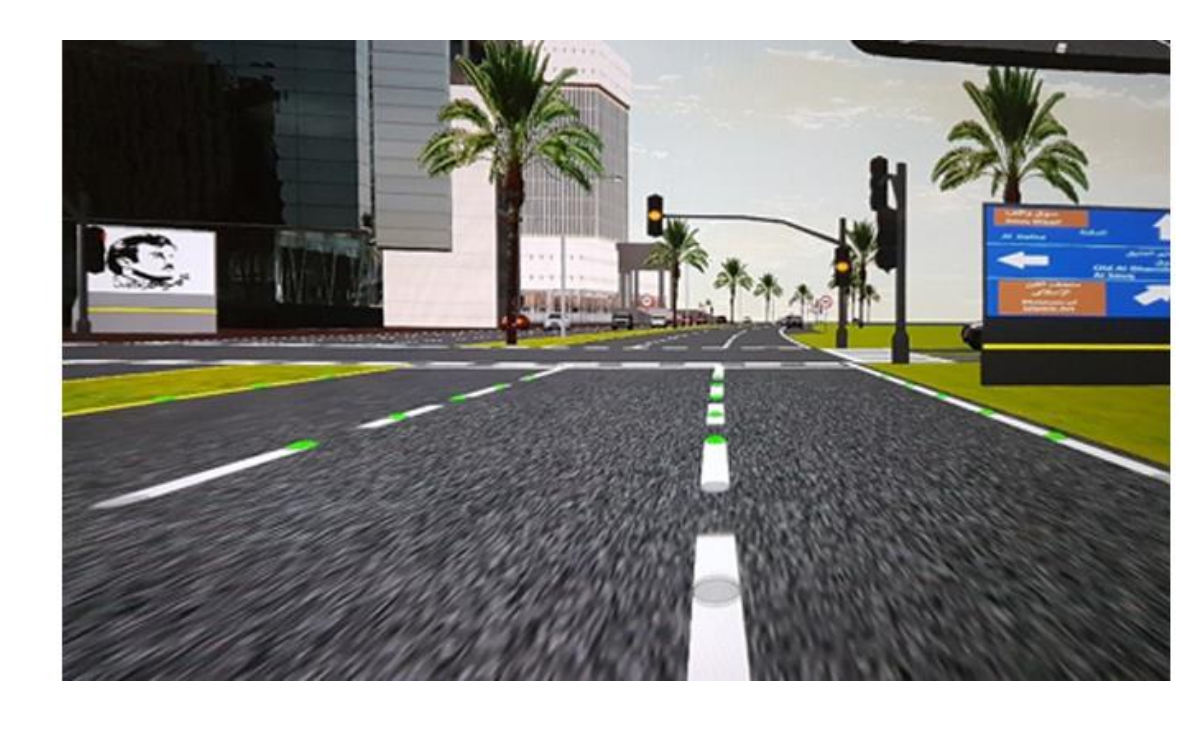

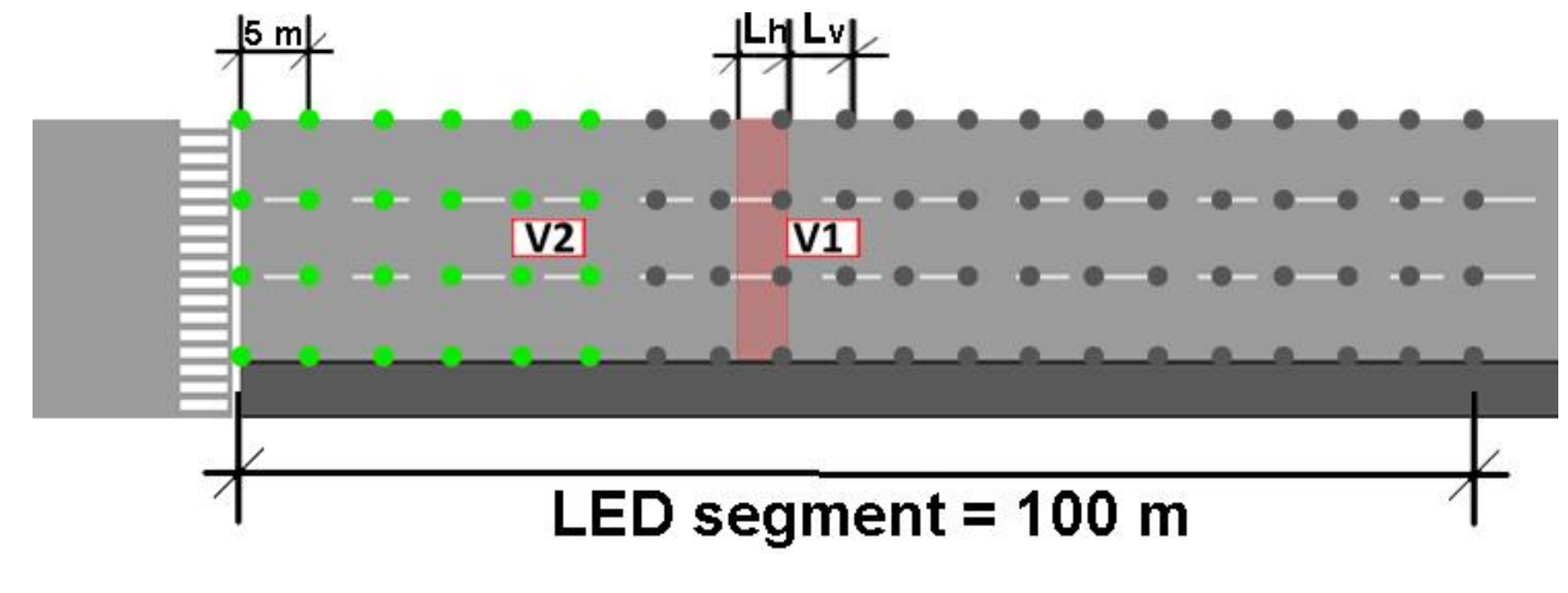

LED lights were turning off one by one in a sequential order with a speed of $56 \mathrm{kph}$ LED lights stretch $=100 \mathrm{~m}$ Spacing between lights $=5 \mathrm{~m}$ 